\title{
FERNANDO VILCHES Y AQUILINO CALZADA: EL SURGIMIENTO DEL SAXOFÓN FLAMENCO EN LA SEGUNDA REPÚBLICA ESPAÑOLA
}

\author{
FERNANDO VILCHES AND AQUILINO CALZADA: \\ THE RISE OF FLAMENCO SAXOPHONE DURING \\ THE SECOND SPANISH REPUBLIC
}

Juan Zagalaz

Universidad de Castilla - La Mancha

\begin{abstract}
Resumen
La reciente aparición de una serie de grabaciones en las que el saxofón, acompañándose de una guitarra flamenca, suple al cantaor, ha generado un cúmulo de informaciones contradictorias en las distintas fuentes. La confusión en torno a la identidad de los músicos implicados, Fernando Vilches y Aquilino Calzada, así como en lugar y momento de edición de las distintas grabaciones, realizadas durante los años 30 y 40, junto a grandes figuras del flamenco como Ramón Montoya, Sabicas y Manolo de Badajoz, ha sido abordada a través de una exhaustiva revisión de hemeroteca, así como de las fuentes escritas y sonoras disponibles. Se ha logrado esclarecer la identidad de Vilches y Aquilino y la relación entre ambos; su actividad como concertistas y las distintas grabaciones, punto de partida de lo que hoy se conoce como fusión flamenca.
\end{abstract}

Palabras clave sión,

Vilches, Aquilino, Montoya, Sabicas, Jazz, Flamenco, fu-

\section{Introducción}

El flamenco, como otras músicas urbanas de tradición oral, ha sido percibido desde el nacimiento de su historiografía con cierto grado de mitificación. El rechazo a métodos de investigación comparativos, como la transcripción y el análisis, por parte de gran porción de los implicados en la realidad flamenca, ha propiciado que la proporción

\begin{abstract}
The recent emergence of a series of recordings, in which the sax, accompanied by a flamenco guitar, takes the role of the cantaor, has generated a corpus of contradictory information within the different sources. The confusion around the identity of the musicians involved, Fernando Vilches and Aquilino Calzada, as well the place and the time of edition of the aforementioned recordings, produced during the 30's and the 40's with historic flamenco players as Ramón Montoya, Sabicas and Manolo de Badajoz, has been approached though an exhaustive newspaper and periodicals research, and other written and sound sources available. We have reached to clear up the identity of Vilches and Aquilino and the relationship between them; their activity as performers and the recordings, showing the beginning of what today is known as fusion flamenco.
\end{abstract}

Key words

Vilches, Aquilino, Montoya, Sabicas, Jazz, Flamenco, fusión

de estudios de este tipo sea muy pequeña en comparación con los de corte histórico o sociológico. Además, la preocupación por la recuperación de figuras históricas del cante, el baile y la guitarra, se ha convertido en tendencia; una búsqueda de lo original, de lo puro, pero de cuyo campo de visión escapan representaciones menos ortodoxas aunque de gran importancia para el devenir del flamenco en épocas más recientes. 
Es el caso de la utilización de instrumentos alternativos en el flamenco. En la actualidad, tras la irrupción en el panorama nacional e internacional del guitarrista Paco de Lucía, ciertos elementos parecen naturalmente integrados en la realidad flamenca, como el cajón, el bajo eléctrico o instrumentos de viento como la flauta o el saxofón. De Lucía decidió incluir el sonido de la flauta en su disco de 1978, Paco de Lucía interpreta a Manuel de Falla, y el del saxo en su obra de 1981, Solo quiero caminar, en el que las influencias del jazz son evidentes ${ }^{1}$. El encargado de llevar a cabo esas grabaciones, que fueron acompañadas de sus correspondientes giras, fue el flautista y saxofonista madrileño Jorge Pardo, quien, desde entonces, viene desarrollando ese concepto de fusión del jazz con el flamenco, siendo su obra y estilo referente además de gozar de una indiscutible vigen$\mathrm{cia}^{2}$. Antes de Pardo, el saxofonista navarro Pedro Iturralde registró tres discos a finales de la década de los sesenta bajo el título Jazz. Flamenco en los que un combo de jazz, con una estética que recuerda al disco de 1961 Olé Coltrane $^{3}$, interpretaba temas con reminiscencias flamencas intercalando la participación de un guitarrista flamenco. Miles Davis y el propio Coltrane también se acercaron al flamenco, a su manera, legitimando este tipo de aproximación y sentando un valioso precedente que sería permanentemente referido en momentos futuros. Sin embargo, los tiempos recientes han ofrecido una nueva perspectiva a raíz de la publicación en distintos recopilatorios de una serie de grabaciones en las que el cantaor es sustituido por un instrumento de viento: el saxofón. Se trata de unos registros realizados, supuestamente, por Fernando Vilches y Aquilino Calzada, más conocido como El Negro Aquilino, junto a guitarristas esenciales en el desarrollo del flamenco, como son Ramón Montoya, Sabicas y Manolo de Badajoz. La información sobre estas grabaciones, nueve cortes en total, es algo confusa tanto a través de las exiguas menciones en la literatura disponible como en los distintos álbumes en las que vienen contenidas, añadiéndose la dificultad de la repetición en los títulos de los temas (milonga, media granaína, fandangos...) así como que distintos temas sean recogidos con títulos diferentes en las fuentes discográficas. Además, resulta llamativo que una aproximación tan original para la época, que contó con la participación de figuras de gran peso en el devenir del arte flamenco, no tenga prácticamente reflejo en la historiografía del género en lo referente a las biografías de Vilches y Cal-

1 POHREN, 1992: 86.

2 Jorge Pardo ha publicado El disco Huellas (Cabra Road, 2012) a comienzos de 2012, compuesto por 18 cortes y en el que han participado grandes figuras del jazz y el flamenco.

3 ZAGALAZ, 2012: 40. zada. Ríos Ruiz ${ }^{4}$, en su Gran Libro de flamenco, publicado en 2002, no menciona a ninguno de los dos músicos en su volumen dedicado a los intérpretes del flamenco. Gamboa, en su obra Una historia de flamenco, menciona de forma sucinta al saxofonista Fernando Vilches, fijando su nacimiento en Cuba y su muerte en Méjico, e indicando que registró la primera versión instrumental de la colombiana en $1933^{5}$; Aquilino es mencionado de pasada en un listado de artistas que participaron en un espectáculo el 15.02.1937 en el Teatro Calderón ${ }^{6}$. Del mismo modo, José Luis Salinas, en su obra Jazz, flamenco, tango: las orillas de un ancho río, pese a reflexionar sobre los puntos de contacto entre jazz y flamenco, entre otras músicas, tampoco menciona este encuentro temprano entre ambos géneros ${ }^{7}$. Calvo y Gamboa en su publicación de 1995, apuntan que "Fernando Vilches, haciendo las veces de un cantaor, grabó varios números acompañado por la guitarra de Ramón Montoya" ${ }^{8}$, aunque no se ofrecen más datos. Germán Herrero, en su análisis pionero de las convergencias y divergencias del jazz y el flamenco, de 1991, tampoco menciona la existencia de Vilches y Aquilino9. Eli y Alfonso informan que Aquilino formó parte de una banda de jazz y que en su repertorio había coplas flamencas, sugiriendo una fusión temprana "fundamental para el devenir del jazz flamenco español” "10, aunque García Martínez, en su libro sobre el jazz en España, Del Fox Trot al Jazz Flamenco, no menciona a ninguno de los dos saxofonistas ${ }^{11}$. El especialista Luis Clemente afirma que en los años 30 "Fernando Vilches, conocido como El Negro Aquilino, llega a grabar su saxo con Sabicas"12, indicando que se trataría de la misma persona, y Manuel Cerrejón data la fecha de nacimiento de Vilches en Cuba en $1895^{13}$. El periódico La Unión, de Jaca, narra en su número de 22.03.1934 un espectáculo en el que participan Aquilino y el saxofonista español Fernando Vilches ${ }^{14}$. En 2011, en un ciclo de jazz promovido por la junta de Andalucía, el prestigioso saxofonista norteamericano David Liebman realizó un homenaje a Ramón Montoya y Fernando Vilches llamado Alborada, en el que participaron el guitarrista flamenco Dani de Morón, Manuel Posadas al contrabajo y Guillermo McGill al cajón,

4 RÍOS RUIZ, 2002b.

5 GAMBOA, 2005: 251.

6 GAMBOA, 2005: 291.

7 SALINAS RODRÍGUEZ, 1994.

8 CALVO y GAMBOA, 1994: 188.

9 HERRERO, 1991.

10 ELI y ALFONSO RODRÍGUEZ, 1999: 138.

11 GARCÍA MARTÍNEZ, 1996.

12 CLEMENTE, 2010: 89.

13 CERREJÓN, 2001.

14 ELI y ALFONSO RODRÍGUEZ, 1999: 138. 
percusión y batería. En el texto promocional, probablemente basado en las informaciones ofrecidas por Manuel Cerrejón en las publicaciones de Pasarela, se indica que los tres discos fueron grabados en 1925, por Montoya y el saxofonista cubano Fernando Vilches ${ }^{15}$.

Como se puede observar, la información sobre ambos saxofonistas y las consiguientes grabaciones resulta contradictoria, en algunos casos; inexistente, en otros. Sin embargo, la originalidad del concepto, así como el nivel de los músicos flamencos con los que estos saxofonistas grabaron y actuaron, requieren una revisión para continuar con la reconstrucción de la historia flamenca, especialmente en los años previos a la Guerra Civil. La actividad desarrollada por ambos músicos, afortunadamente, dejó rastro en la prensa de la época, lo que permite reconstruir, de una forma más o menos detallada, la sucesión de acontecimientos que desencadenó el auge del saxofón flamenco, así como su recepción, su contexto, y hechos derivados, como la realización de grabaciones. Por lo tanto, el objetivo de este artículo es observar la actividad de los músicos Fernando Vilches y Aquilino Calzada a través de la prensa y las grabaciones en las décadas de 1920 y 1930, con especial intensidad en el año 1932, con el fin de esclarecer tanto la identidad de ambos intérpretes como el número, la autoría y fecha aproximada de las distintas grabaciones. Se persigue así reconstruir un legado histórico que marca el inicio de la fusión de dos músicas urbanas, como el jazz y el flamenco, en la España de la Segunda República.

\section{Vilches y Aquilino, una doble biografía a través de la prensa de la Segunda República}

Fernando Vilches Silva nació el 29.10.1897 en Jaén, según consta en el Archivo de la Secretaría de Gobernación de México ${ }^{16}$, donde acabaría llegando el 27.07.1939 como exiliado político. Sus primeras referencias como músico las encontramos en otro documento oficial. Se trata del Diario Oficial del Ministerio de la Guerra publicado el 30.07.1924 ${ }^{17}$.

15 Programa del ciclo de conciertos disponible on line: http://www.juntadeandalucia.es/cultura/teatrocentral/pdf/TC_ JAZZ_NOV_2011.pdf [Última consulta: 13.12.2012.]

16 Información disponible on line en la web de la Secretaría de Estado de Cultura dependiente del Ministerio de Educación, Cultura y Deporte, donde se registran los movimientos migratorios iberoamericanos. En el caso de Fernando Vilches, la información procede del Archivo general de la Nación de México: http://pares.mcu.es/ MovimientosMigratorios/detalle.form?nid=18157 [Última consulta: 18.12.2012]

17 Diario oficial del Ministerio de Guerra (Miércoles 30.07.1924): Tomo III, 300 .
En él, se especifican los nuevos destinos a distintos músicos, entre los que se encuentras mencionado Fernando Vilches Silva, como músico de segunda, trasladado desde el Regimiento Extremadura, 15, al Regimiento Rey, 1. La ubicación histórica de este Regimiento en la capital pudo ser la causa de la llegada de Vilches a Madrid, lugar donde desarrollaría posteriormente su labor compositiva y concertística. En 1928, encontramos las primeras referencias en prensa del saxofonista jiennense. Se trata de la emisión en Unión Radio de la actuación de la Orquesta Vilches, probablemente desde el estudio, que se produjo el día 6 de junio a las 14:00 ${ }^{18}$, interpretando un repertorio variado y que incluía composiciones del propio Vilches ${ }^{19}$. Esto corroboraría que ya estaba bien posicionado y considerado como músico, aunque se desconoce la ubicación habitual de la orquesta. Las siguientes noticias que encontramos vuelven a ser de la Orquesta Vilches, esta vez en El Heraldo de Madrid de 1932, en la que la agrupación aparece tocando en el Pleyel, mencionando su rotundo éxito y a su cantor $\mathrm{Morel}^{20}$.

Por su parte, Aquilino Calzada González, más conocido como El Negro Aquilino, tampoco cuenta con un gran reflejo en la literatura académica especializada. Díaz Ayala, uno de los investigadores que de manera más profunda se ha ocupado de la música cubana, define a Aquilino como "otro cubano que se destacó en España" 21 , sin ofrecer datos como el lugar o fecha de nacimiento. En el diccionario enciclopédico de la música en Cuba, de Radamés Giró, se indica 1910 como fecha posible de nacimiento en Guantánamo,22 si bien en un artículo del periódico La Estampa, de 1935, se indica que el lugar de procedencia es Masareillo ${ }^{23}$, en la parte oriental de $\mathrm{Cuba}^{24}$. La ausencia de información contrasta con la intensa actividad que desarrolló Aquilino a partir de 1932 en España, ya que alcanzó una gran popularidad en un breve periodo de tiempo, quedando ampliamente reflejado en la prensa del momento. Irrumpió en el panorama musical nacional en la primavera de 1932, con su Banda de Estrellas Negras. Diversos periódicos registran el éxito cosechado por la formación en Albacete en abril ${ }^{25}$, sin mencionar explícitamente al músico cubano. El día 18.05.1932, el diario El

18 En La Voz (05.05.1932): 6; La Libertad (05.05.1932): 7, y El Imparcial (05 y 06.05.1932): 10 y 8

19 La Libertad (05.05.1932): 7

20 El Heraldo (21.01.1932): 6

21 DÍAZ AYALA, 2001: 41.

22 RADAMÉS, 2007: 62.

23 Puede que se trate de Manzanillo, localidad cercana a Guantánamo.

24 La Estampa (09.02.1935): 33.

25 El Heraldo (11.04.1932): 13; Luz (11.04.1932): 10; El Siglo futuro (11.04.1932): 3 . 
Heraldo publica la noticia de la actuación de las Estrellas Negras en Talavera de la Reina, donde ya se menciona la sobresaliente actuación de Aquilino:

Con motivo de la feria actuó ayer tarde la cuadrilla cómicoartísticomusical Estrellas Negras, que obtuvo un éxito resonante [...]Finalmente, trabajó el gran espectáculo banda de Estrellas Negras, que, como siempre, fué ovacionada durante el concierto de forma clamorosa, especialmente el ya popular negro Aquilino, que con sus famosos fandanguillos en saxofón obtuvo un triunfo y escuchó delirantes ovaciones. ${ }^{26}$

En esta reseña se observa que, efectivamente, tanto la banda como el propio Aquilino comenzaban a adquirir cierta popularidad, así como la característica más determinante del saxofonista: el acercamiento al repertorio flamenco a través del saxofón, un instrumento completamente ajeno a este arte en aquella época. Sin embargo, esto sólo fue el comienzo.

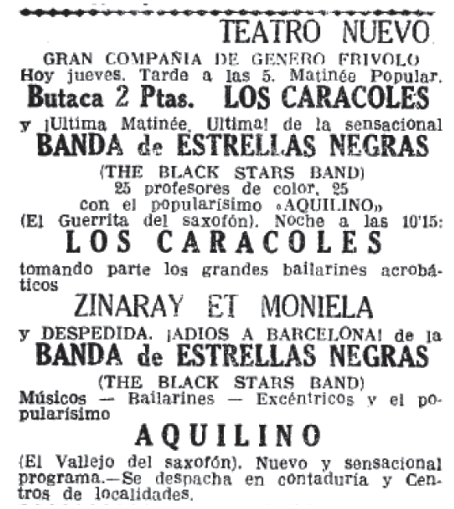

Ilustración 1: Agenda en la que aparece la Banda de Estrellas Negras, en el diario La Vanguardia (15 y 16.06 .1932$)$

La prensa le atribuye el sobrenombre de "El Vallejo del Saxofón" ${ }^{27}$, en alusión al famoso cantaor de la época Manuel Vallejo, entre otros apelativos. Las crónicas presentan también cada vez más detalles, ofreciendo el repertorio ejecutado por el saxofonista. Así, en su actuación en Sevilla el 04.07.1932, Aquilino interpretó, entre otras piezas, fandanguillos, guajiras y milongas ${ }^{28}$. Es de nuevo el diario

26 El Heraldo (18.05.1932): 10.

27 La Vanguardia (15.06.1932): 16.

28 La Libertad (05.07.1932): 7.
El Heraldo el que detalla las características del espectáculo de Las Estrellas Negras tras su presentación en Madrid, dedicando un extenso artículo. En él, el cronista Don Nino, relata el gran éxito obtenido por Las Estrellas Negras, compuesta por veinte profesores venidos de América, mencionando los éxitos de Albacete, Barcelona y Sevilla ${ }^{29}$, previamente apuntados. Señala la asistencia de 14.000 espectadores y el hecho de que se agotaran las entradas horas antes del comienzo. Además, detalla la estructura del espectáculo, compuesto por toreo, la actuación de una cuadrilla cómica y, finalmente, la actuación de las Estrellas Negras ${ }^{30}$. Tras los primeros compases de la actuación, en los que la banda interpretó el Himno de Riego y el Sitio de Zaragoza, prosiguió la sección dedicada a los solistas, entre los que se encontraba Aquilino:

Todos los caracteres de apoteosis al destacarse la personalidad de tres solistas formidables. Uno de clarinete, otro de cornetín y el negro Aquilino, conocido por "el Marchena del saxofón". Aquilino alcanzará dentro de poco tiempo el renombre que corresponde a los grandes artistas. El saxofón canta más que interpreta, con toda su emoción, con todo su sentimiento, el cante jondo, el más flamenco de todos, el que sabe llegar al alma. Es la voz humana la que llega a nuestros oídos, en unos fandanguillos, en unas guajiras, en unas milongas $\mathrm{y}$ en medias granadinas. Aquilino, para quien fueron las aclamaciones más entusiastas, tuvo que saludar repetidamente desde el centro del anillo. ${ }^{31}$

Este rotundo éxito en la capital hizo que la banda repitiera actuación al día siguiente. Aquilino comienza a ser reflejado como el Saxofón Humano ${ }^{32}$, y es sacado en hombros por los asistentes más entusiastas al terminar la segunda actuación madrileña ${ }^{33}$. Este triunfo en la capital propició que se disparara el número de actuaciones durante ese verano, repitiendo en Madrid y visitando otros puntos del territorio nacional. En diversos anuncios es presentado como la revelación artística del año ${ }^{34}$, y llega a participar en un festival benéfico a favor de los pobres del distrito del Hospital ${ }^{35}$, siendo anunciado como "el famosísimo negro Aquilino, de la Agrupación musical «Las Estrellas Negras» ${ }^{36}$.

\footnotetext{
29 El Heraldo (15.07.1932): 10.

30 El Heraldo (15.07.1932): 10.

31 El Heraldo (15.07.1932): 10.

32 El Heraldo (18.07.1932): 10.

33 Luz (18.07.1932): 10.

34 El Heraldo (04 y 05.08.1932): 5 y 5.

$35 \mathrm{Luz}$ (08.09.1932): 11.

$36 \mathrm{Luz}$ (08.09.1932): 11.
} 
El tipo de espectáculo que fueron desarrollando las Estrellas Negras, integrando toreo, comicidad y música, no era original de la agrupación. En aquel momento, el empresario Rafael Dutrús "Llapisera", antiguo torero y corresponsable de la creación y auge de las cuadrillas cómicas junto a José Colomer y Carmelo Tusquellas en $1916^{37}$, presentaba su espectáculo Los Calderones, al menos desde finales de 1931, actuando en Valencia el 16 de noviembre de aquel año ${ }^{38}$. A partir del mes de marzo de 1932, Los Calderones comienzan a estar presentes en distintas plazas de España, como Valencia, Castellón, Puerto de Santa María, Murcia, Albacete, Alicante, Cartagena o Burgos, reflejadas en distintas publicaciones periódicas ${ }^{39}$ y cosechando gran éxito, si bien no tan enorme como el observado en el caso de Aquilino y las Estrellas Negras. La irrupción en el mercado de esta última, con gran fuerza a partir de mayo, hizo que Dutrús buscara soluciones ante la feroz competencia. Así, en la segunda mitad del mes de agosto de 1932, en pleno apogeo de la banda de Aquilino, Llapisera presenta en Toledo las innovaciones introducidas en su espectáculo, referidas a la sección musical de la que Los Calderones eran responsables:

La banda Los Calderones dio un concierto excelente, en el que los profesores que la componen demostraron una vez más su maestría, y como modificación fue servido un número de cante "jondo". Esto de cante es un decir, porque si bien es verdad que un buen guitarrista tocó por fandanguillos, medias granadinas, etc., el que cantó no fue un hombre, sino un saxofón. Ambos lo hicieron maravillosamente y el público los ovacionó con entusiasmo, así como a la banda en general y a su director artístico, Llapisera. $^{40}$

Se omiten los nombres del saxofonista y el guitarrista, si bien se observa una clara respuesta al éxito obtenido por Aquilino interpretando flamenco con el saxofón. Pero este anonimato se resolvería dos páginas después, en el mismo

37 ZABALA, 2003: 81.

38 La Libertad (17.11.1931): 2.

39 La Fiesta Brava (28.01.1932): 4; Luz (12.02.1932): 6; Luz (07.03.1932): 11; El Imparcial (08.03.1932): 4; La Voz (14.03.1932): 9; Luz (14.03.1932): 10; La Libertad (15.03.1932): 9; La Fiesta Brava (18.03.1932): 6; La Voz (19.03.1932): 8; Luz (19.03.1932): 10; El Imparcial (22.03.1932): 4; La Fiesta Brava (25.03.1932): 3 - 4; La Voz (28.03.1932): 5; Luz (28.03.1932): 7; El Imparcial (29.03.1932): 6; La Voz (04 .04.1932): 9; Luz (04.04.1932): 7; La Libertad (05.04.1932): 8; Luz (11.04.1932): 7; La Voz (05.05.1932): 9.

40 La Libertad, 20.08.1932, p. 9. periódico ${ }^{41}$, ya que la maquinaria publicitaria de Dutrús se había puesto en marcha para promocionar su respuesta a los constantes triunfos del cubano y su banda:

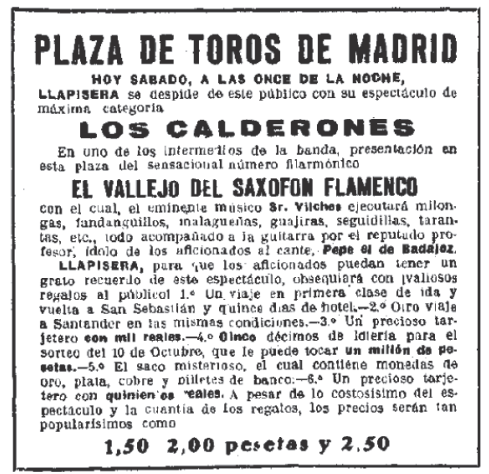

Ilustración 2: Publicidad en el periódico La Libertad (20.08.1932), anunciando el espectáculo de Los Calderones con Fernando Vilches

Esta publicidad del espectáculo, que tendría lugar la noche del 20.08.1932 en Madrid, esclarece la identidad de los dos músicos que actuaron la noche anterior en Toledo. Se trató del Sr. Vilches, al saxofón, junto a Pepe de Badajoz, a la guitarra, en clara respuesta a la propuesta de Aquilino. Además, se emplea la nominación de Vilches como El Vallejo del Saxofón, tal y como había ocurrido con Aquilino previamente. También se detalla el repertorio, integrado por milongas, fandanguillos, malagueñas, guajiras y tarantas ${ }^{42}$. La fórmula de Llapisera estaba clara, aunque la verdadera innovación estaba en la introducción de un guitarrista flamenco, ya que Aquilino solía acompañarse de un pianista. La crónica del día siguiente resalta que "el acoplamiento de estos dos instrumentos en la interpretación de la ópera flamenca es una prueba más del ingenio de Llapisera" ${ }^{43}$.

Este contraataque del empresario valenciano tuvo cumplida réplica por parte de Aquilino. El saxofonista cubano retó a Vilches a medir fuerzas en la plaza de toros de Madrid $^{44}$, a través de una carta publicada en El Heraldo el día 30.08.1932, en la que se autonombraba creador del cante hondo en saxofón. Incluso mencionaba a Llapisera e instaba a Vilches a que éste se pusiera en contacto con su empresario, Manuel Gómez ${ }^{45}$ :

41 La Libertad (20.08.1932): 11. 42 La Libertad (20.08.1932): 11. 43 La libertad (21.08.1932): 8. 44 El Heraldo (30.08.1932): 13. 45 El Heraldo (30.08.1932): 13. 


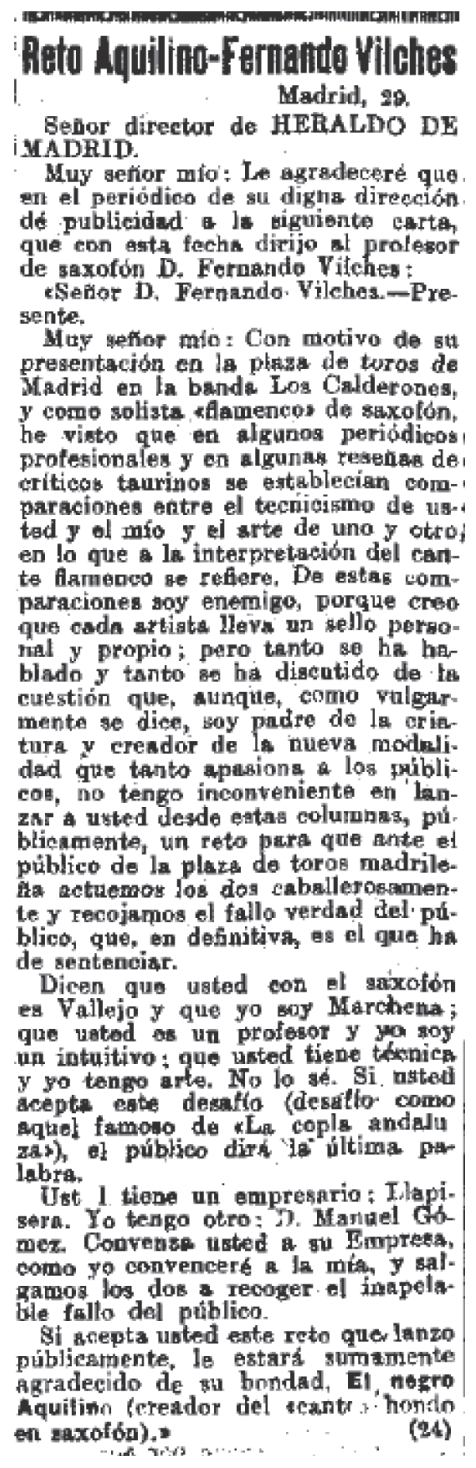

Ilustración 3: Recorte de El Heraldo (30.08.1932), en el que aparece el reto lanzado por Aquilino a Fernando Vilches

El día dos de septiembre, varios diarios recogieron la noticia de la aceptación del reto por parte de Vilches ${ }^{46}$. Aparecía en forma de publicidad anunciando que El Vallejo del Saxofón Flamenco había aceptado el reto lanzado por el popularísimo Negro Aquilino, e incluía más información del

46 El Heraldo (02.09.1932): 5; La Voz (02.09.1932): 2.; La Libertad (03.09.1932): 9. envite. Se celebraría el día 3 de septiembre a las once de la noche en la plaza de toros de Madrid, con la actuación de Los Calderones, La Banda de Estrellas Negras y con la cooperación de todos los artistas cómicos que acompañaban a ambas bandas. En la publicidad, se hace también hincapié en lo popular de los precios dado el alto coste del espectáculo: 


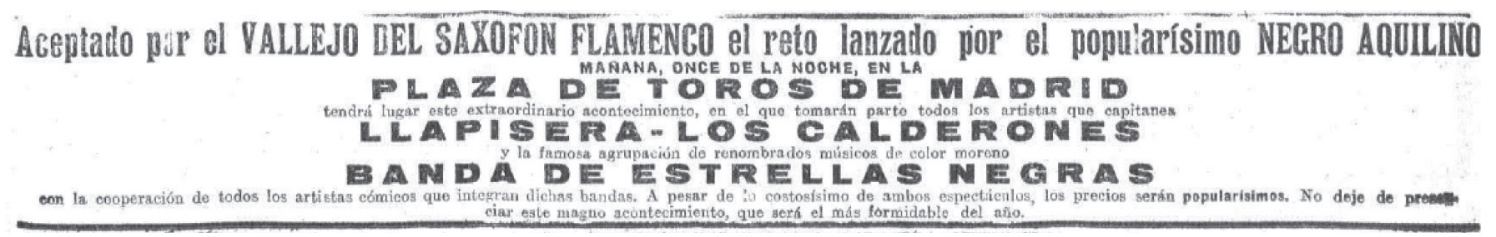

Ilustración 4: Publicidad del reto Aquilino Vilches, en El Heraldo (02.09.1932): 5

De nuevo, varios periódicos se hicieron eco del espectáculo en los días posteriores. En La Libertad, se relata cómo la plaza se sumió en un gran silencio cuando le llegó el turno al creador del cante flamenco con saxofón, Aquilino ${ }^{47}$. El cubano interpretó, según esta fuente, fandanguillos, guajiras, medias granadinas y la canción de Juan Simón ${ }^{48}$ acompañado al piano. Vilches, por su parte, actuó acompañado de nuevo por Pepe de Badajoz, y es calificado como excelente imitador $^{49}$. En El Heraldo se detalla el repertorio de Vilches, integrado por milongas, fandanguillos y guajiras ${ }^{50}$. Aquilino, por su parte, interpretó, según El Heraldo, una guajira, un fandanguillo, una colombiana y una media granadina que, aparentemente, dedicó a Llapisera ${ }^{51}$. Luz denomina al evento festival filarmónico flamenco ${ }^{52}$, destacando la buena actuación de ambos solistas. Los tres periódicos coinciden de manera contundente en que el vencedor de la contienda fue Aquilino, quien salió reforzado tras la realización espectáculo. La apuesta de Llapisera por copiar la estrategia de su rival no parecía haber funcionado, aunque el evento en sí fuera una operación empresarial ingeniosa y que traería consecuencias en el futuro próximo. A nivel artístico, los repertorios de los dos solistas estaban compuestos por composiciones similares, que además, como es el caso de la milonga o la guajira, están muy presentes en los catálogos de las grabaciones de los distintos artistas flamencos del momento. Si Vilches había copiado directamente el repertorio a Aquilino, la novedad venía dada por el acompañamiento, con guitarra flamenca ${ }^{53}$,

47 La Libertad (04.09.1932): 6.

48 Puede que se trate de una vidalita recogida en el catálogo de La Voz de su Amo de 1932, grabada por El Niño de Marchena y con código de catálogo AE 3012 o de un palo no especificado, grabado por Angelillo y con referencia AE 1847.

49 La Libertad (04.09.1932): 6.

50 El Heraldo (05.09.1932): 12.

51 El Heraldo (05.09.1932): 12.

52 Luz (05.09.1932): 11.

53 Vilches tuvo en esa etapa inicial con Los Calderones como guitarrista a Pepe de Badajoz, hermano de Manolo de Badajoz. Posteriormente, entre 1934 y 1941 trabajó acompañando a la Argentinita, para luego establecerse en Méjico entre 1940 y 1946. Posteriormente regresó a España, y hasta su muerte en 1970 siguió en activo, siendo considerado un excelente profesional. En RÍOS RUIZ, 2002a: 379. aunque la elección de los temas bien podía estar determinada por los gustos imperantes en ese momento concreto dentro del mundo del flamenco. Después del reto, Aquilino siguió muy activo, con más actuaciones en ciudades como Calahorra, Cuenca, Santoña o Salamanca ${ }^{54}$, además de Madrid, así como en los premios del toreo celebrados el 8 de octubre ${ }^{55}$, lo que muestra la gran popularidad del músico. Poco después, la Banda de Estrellas Negras adquiere compromisos puntuales para actuar en el Teatro Circo Price ${ }^{56}$, en un espectáculo variado y circense en el que también estaban incluidos Los Leones de Ivanoff ${ }^{57}$. En su despedida del teatro, el día 28 de octubre, está anunciada la presencia de Cepero, Andalucita, Aurorita Imperio, Canalejas y Sabicas, entre otros ${ }^{58}$, si bien no fue su única experiencia con músicos flamencos durante esas semanas. La participación de Aquilino y las Estrellas Negras en La Latina en beneficio de Antonio Algafán, contaría de nuevo con la presencia de Cepero, de El Faro, Corruco de Málaga, Chato de las Ventas y Niño de Valdepeñas ${ }^{59}$. Encontramos también a la Banda en otro festival benéfico, que se llevaría a cabo el 27 de noviembre en el Teatro Pavón para los pobres del distrito de la Inclusa ${ }^{60}$, lo que muestra la preocupación de Aquilino por mantenerse en escena de manera continua. Con respecto a Vilches, la prensa no refleja una gran actividad, más allá del concierto de Los Calderones en Barcelona el 18.09.1932, donde El Vallejo del Saxofón actuó junto a un guitarrista de nombre desconocido ${ }^{61}$.

Encontramos, en este punto, un auge del saxofón interpretando repertorio flamenco a modo de cantaor sin precedentes es la historia, potenciado por la popularidad y la espectacularidad del concepto de Aquilino, desenvolviéndose en contextos taurinos y masivos, y acercándose al repertorio

54 La Libertad (07.09.1932): 6; La Libertad (09.09.1932): 7; La Libertad (20.09.1932): 8; El Heraldo (22.09.1932): 11.

55 La Libertad (08.10.1932): 7.

56 Luz (08.10.1932): 2.

57 El Heraldo (22.10.1932): 5.

58 El Imparcial (28.10.1932): 5.

59 La Libertad (05.11.1932): 9.

60 El Heraldo (24.11.1932): 5.

61 La Fiesta Brava (23.09.1932): 3. 
flamenco más en boga. Además, el contacto con el mundo flamenco, inicialmente realizado por Vilches con Pepe de Badajoz, se continuó con las distintas experiencias de Aquilino con varios músicos en los últimos meses de ese año 1932. La dimensión comercial de ese acercamiento al flamenco es innegable, pero también lo es el contacto entre estos saxofonistas y representantes del mundo flamenco de la época, lo que, de uno u otro modo, acabaría sentando un precedente y transfiriendo elementos de índole cultural y musical. Muestra de esto es la grabación que se debió producir durante ese último tercio de 1932, publicada por la compañía del gramófono y en la que Fernando Vilches registraba su saxo junto a la guitarra de Ramón Montoya, uno de los guitarristas más importantes del momento y, a posteriori, de la historia del flamenco ${ }^{62}$. Se trató, al menos inicialmente, de dos tomas registradas en un disco de 78 r.p.m., Por Fandangos y Por Peteneras, tal y como se puede observar en la galleta del disco original ${ }^{63}$, así como en la publicidad lanzada el día de Nochebuena de $1932^{64}$; aunque un anuncio posterior, previo al día de Reyes, aclara los títulos de ambas piezas: Mi Colombiana y Flor de Peteneras ${ }^{65}$. En el diario $L u z$ del 11.01.1933, encontramos una crítica del disco de Vilches y Montoya, en la que el autor de la misma establece conexión entre la voz humana y el saxofón, lo que le habría valido a este instrumento para desarrollarse de acompañante a protagonista ${ }^{66}$. Se aclara que esta similitud ocurre especialmente en el jazz, y que aunque "Vilches, con su saxófono, trata de sustituir al cantante flamenco [...] el saxófono no puede sustituir al flamenco como reemplaza al negro" ${ }^{" 67}$ :

Aquilino, por su parte, inició el nuevo año con cierta actividad. El día 28 de enero, el saxofonista cubano reapareció en el Circo Price con una nueva denominación para su banda, Rondalla Electra, en un Campeonato de baile de resistencia ${ }^{68}$. Sin embargo, parece que esta nueva denominación (o formación, o ambas) no tuvo demasiado reco-

62 Ramón Montoya fue una figura determinante para el desarrollo de la guitarra flamenca. Recibió clases del Maestro Malagueño y puntualmente de Miguel Borrull. Manuel Cano resalta, su afán por la perfección técnica, por lograr un sonido personal y por la independencia artística. En BLAS VEGA \& RÍOS RUIZ (1988): 508-809.

63 Este disco, publicado por la compañía del Gramóno, inluye los temas Por Fandangos y Por Peteneras, ambos compuestos por Fernando Vilches y Enrique Bregel, e interpretados por Fernando Vilches al saxofón y Ramón Montoya a la guitarra. No se especifica en la galleta el año de edición, aunque su número de catálogo AE 4136 y su presencia en los distintos catálogos indica a que se publicó a finales de 1932 .

64 ABC (24.12.1932): 6.

65 El Heraldo (05.01.1933): 10.

66 Luz (11.01.1933): 4.

$67 \mathrm{Luz}(11.01 .1933): 4$

68 El Heraldo (27.01.1933): 5.; El Sol (28.01.1933): 2.
La Voz de su Amo.-AE 4.136: La similitud de la voz del saxófono con la voz humana ha promovido su enorme desarrollo, desde mero instrumento acompañante a instrumento principal, protagonista. Sobre todo en la música de "jazz". En este disco, Vilches, con su saxófono, trata de sustituir al cantante flamenco en dos trozos, "Por peteneras" y "Por fandangos", acompañado del guitarrista Montoya. Pero aunque el saxófono no puede sustituir al flamenco como reemplaza al negro, es un ensayo curioso.

Ilustración 5: Crítica del disco de Vilches con Montoya, en el periódico La Libertad (11.01.1933): 4

rrido, ya que en marzo encontramos el nuevo espectáculo de Llapisera, que, de forma inteligente, institucionalizó lo acontecido el año anterior con el reto, integrando a Los Calderones con la Banda de Estrellas Negras, y bautizándolo como Los Ases. La primera referencia la encontramos en El Heraldo del 20.03.1933, en la que se describe el devenir del espectáculo, en el que "obtuvieron un éxito señaladísimo los solistas del saxofón Fernando Vilches y el Negro Aquilino" ${ }^{69}$. Llapisera había unido a los antiguos contendientes en su nuevo espectáculo, con el fin de atraer a más público y eliminarse competencia. Este concierto de Barcelona, celebrado el 19 de marzo, supuso un gran éxito a pesar de que el público silbó desaforadamente al grupo de Llapisera $^{70}$, lo que hizo que el triunfo posterior tuviera aún más mérito ${ }^{71}$. De las crónicas de la actuación de la formación en Valencia, unos días después de la de Barcelona, se desprende que tanto Aquilino como Vilches estaban acompañados por Beltrán $^{72}$, pianista, recibiendo continuas ovaciones ${ }^{73}$, abandonándose así la aproximación inicial con guitarra flamenca que el propio Vilches había empleado. Durante los siguientes meses, la banda se mantuvo activa tocando en ciudades como Madrid, Sevilla o Burgos ${ }^{74}$, si bien se muestran ciertos síntomas de agotamiento en el concepto. La efusividad mostrada por la prensa durante 1932 no se repite este año, puede que por haber perdido su carácter innovador. Así, Llapisera intentó revivir el momento cumbre del año anterior, reeditando el reto de Aquilino a Vilches por segunda vez. Ocurriría el 8 de octubre en Vista Alegre, instando desde las

69 El Heraldo (20.03.1933): 10.

70 La Fiesta Brava (24.03.1933): 6.

71 La Fiesta Brava (24.03.1933): 6.

72 El Heraldo (27.03.1933): 10.

73 Luz (27.03.1933): 10.

74 ABC (04.06.1933): 36; El Heraldo (06.07.1933): 10; La Fiesta Brava (14.07.1933): 7. 
páginas de $\mathrm{ABC}$ al público a "presenciar este nuevo reto de Aquilino al gran Vilches, porque seguramente será el más flamenco de su vida"75.

Este segundo año de interacción entre Aquilino y Vilches no fue tan exitoso para el cubano como el anterior, aunque parece claro que ambos saxofonistas compartieron tiempo y experiencias. A comienzos de 1934, encontramos a Vilches tocando en un espectáculo en la localidad de Almansa ${ }^{76}$, en el que también participó el cantaor Canalejas, mostrando una vez más su mayor vinculación con el mundo del flamenco. La presencia tanto de Vilches como de Aquilino se reduce drásticamente en la prensa de ese año. Tras separarse de Llapisera ${ }^{77}$, ambos se unieron para generar un espectáculo al que llamaron El Número 13, dirigido por Manuel Lázaro ${ }^{78}$. Básicamente, la estructura era la misma, si bien el éxito cosechado en la Plaza de Toros de Tetuán no fue rutilante ${ }^{79}$. En Barcelona, sin embargo, la banda tuvo que repetir su actuación en las Arenas, aunque también fue catalogado por la prensa como "buen" éxito ${ }^{80}$, lejos de los clamorosos triunfos del 32 e, incluso, del 33. Además, en pos de una mayor espectacularidad, comenzamos a encontrar a Aquilino, además de como músico, de matador en varios de los eventos, como el de Barcelona, Ciudad Real o Madrid ${ }^{81}$.

Sin embargo, se observa un auge en las apariciones radiofónicas de ambos músicos, con especial insistencia en el caso de Aquilino. En julio de ese año, se retransmite en Unión Radio las grabaciones realizadas por Aquilino junto a Beltrán y publicadas por Odeón ${ }^{82}$, conformadas por una milonga y una media granadina. En agosto, encontramos la retransmisión del tema "Granada Cañî" ${ }^{3}$, de Vilches y Bregel, con orquesta, y a finales de noviembre, una actuación de Aquilino junto al guitarrista Manolo Martel ${ }^{84}$, en un nuevo contacto con el flamenco por parte del saxofonista cubano. A finales de ese año también encontramos a Aquilino tocando un recital en Unión Radio ${ }^{85}$, aunque no es descartable que se tratara de alguna repetición de eventos previamente emitidos.

75 ABC (08.10.1033): 59.

76 El Heraldo (25.01.1934): 4.

77 El Heraldo (06.08.1934): 6.

78 La Libertad (05.08.1934): 4.

79 Los dos de arriba más

80 La Fiesta Brava (03.08.1934): 7.

81 ABC (14.08.1934): 44; Luz (07.09.1934): 4; El Heraldo (07.09.1934): 4; La Fiesta Brava (03.08.1934): 7.

82 Ondas (21.07.1934): 27.

83 Ondas (11.08.1934): 26.

84 Ondas (17.11.1934): 9; La Libertad (20.11.1934): 10; La Libertad (21.11.1934): 10.

85 El Heraldo (27.12.1934): 5.
El año 1935 parece ofrecer un leve resurgir tanto de Vilches como de Aquilino, que ya son figuras artísticas consolidadas, aunque también se genera un cierto rechazo del público al concepto de saxofón flamenco, como se puede observar en Gracia y Justicia. La cuadrilla cómica Unión Republicana, según el artículo publicado el 20.04.1935, tenía pensado contratar a Aquilino, descartando la opción porque "eso del saxofón está muy visto" 86 . Vilches, por su parte, comenzó el año en contacto de nuevo con el flamenco, participando en un Festival a beneficio de los presos políticos el domingo 20 de enero ${ }^{87}$. En dicho evento, organizado por el grupo artístico de Cultura Popular, intervendrían grandes nombres del género, como Valderrama, Sabicas y Ramón Montoya ${ }^{88}$. En otro evento, producido el 2 de febrero de ese mismo año, Vilches actuó en el Cine Montecarlo junto a Pena (hijo), Montoya, el Niño de Marchena y otros artistas, en lo que se define en la nota de agenda como "gran velada flamenca" 89 . Encontramos también a Vilches en este punto con bastante presencia en el entorno radiofónico. El día 12 de febrero ${ }^{90}$ realizaría un recital de saxofón en Unión Radio, en el que interpretaría, según el programa, temas titulados "Mis fandangos", "Granadina gitana" o "Milonga", entre otros ${ }^{91}$. Es muy probable que la única foto del saxofonista que se ha localizado ${ }^{92}$, publicada en Ondas el 23.02.1935 ${ }^{93}$, proceda de esta actuación en Unión Radio. Aparece acompañado de un pianista ${ }^{94}$, por lo que es probable que, en esta ocasión, no actuara junto a ningún guitarrista flamenco:

Aquilino, por su parte, aparece retratado en La Estampa en el marco de un reportaje llamado Negros en Madrid, el 09.02.1935. En dicho reportaje, encontramos un párrafo dedicado al artista cubano, en el que se afirma que se casó en enero de 1934 con Carmen Aguilar, valenciana, con quien vivía en Madrid. Además, estaría a punto de convertirse en padre. Puede que esta circunstancia motivara en parte el lapso de dos meses hasta la próxima noticia del

86 Gracia y Justicia (20.04.1935): 4.

87 La Libertad (19.01.1935): 7.

88 La Libertad (19.01.1935): 7.

89 La Voz (02.02.1935): 7.

90 La Libertad (12.02.1935): 10.

91 Ondas (09.02.1935): 9.

92 La única, con excepción de las dos fotos integradas en la documentación de entrada en Méjico como exiliado político en 1939. La comparación de las tres imágenes ha permitido corroborar la identidad del músico, así como contrastar la información de la documentación con el Registro Civil de Jaén, que confirmó la veracidad del nombre, lugar y fecha de nacimiento de Fernando Vilches Silva.

93 Ondas (23.02.1935): 4.

94 Podría tratarse de Enrique Bregel, con quien Vilches estuvo muy vinculado, aunque no se ha podido precisar este extremo. 


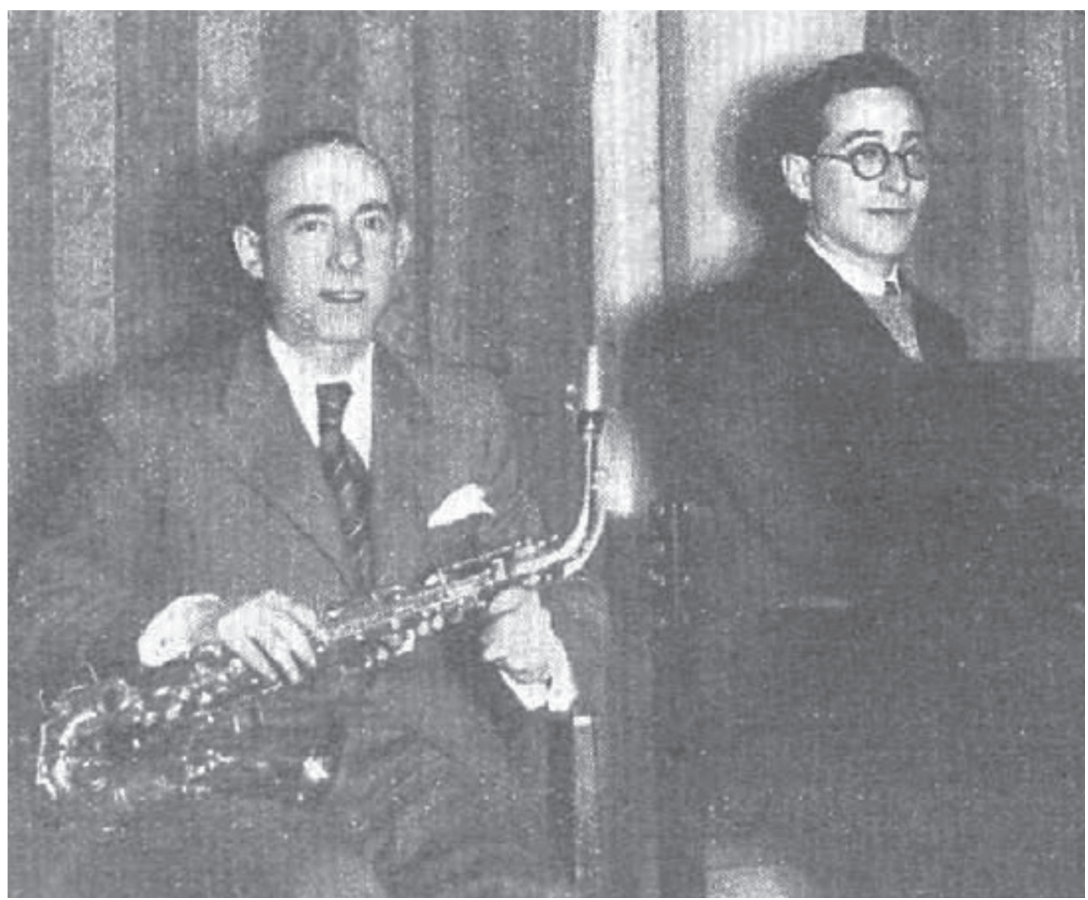

Ilustración 6: Fernando Vilches en 1935, en su Recital para Unión Radio, en Ondas (02.02.1935)

saxofonista, en abril de ese mismo año. Sería como una de las novedades de la reposición de la revista "iHip, hip, hurra!", de Vela y Sierra y el maestro Guerrero ${ }^{95}$, en la que Aquilino participaría interpretando malagueñas, fandanguillos, granadinas y bulerías con el saxofón ${ }^{96}$.

Puede que la actividad tanto de Aquilino como de Vilches no fuera lo rentable que ambos habrían deseado, y eso pudo propiciar su retorno a las filas de Llapisera, que planteó un nuevo espectáculo al que llamó Universal y cuya presentación en Madrid se produjo el sábado 29.06.1935 ${ }^{97}$. En las crónicas de este evento, se detalla que el nuevo director de la agrupación era Harry Flemming, y que tanto Vilches como Aquilino fueron ovacionados ${ }^{98}$. Se detalla también el giro que el artista coreográfico Flemming había dado a la parte musical, calificada de modernísimo jazz en el que estaban integrados los solistas Aquilino, Vilches y Pedro Blanco 99 . El Heraldo califica el espectáculo de "gran éxito", aunque el papel de Aquilino y Vilches pierde pro-

95 El Sol (12.04.1935): 6.

96 El Sol (12.04.1935): 6.

97 ABC (29.06.1935): 48.

$98 A B C(30.06 .1935): 53$.

99 La Libertad (30.06.1935): 4. tagonismo a favor del jazz que dirigía Harry Flemming ${ }^{100}$. Una semana después, tras el éxito cosechado, la formación repitió actuación en Madrid, y en una crónica publicada en La Libertad, el columnista anota que "de un espectáculo viejo y que estaba a punto de morir, tal vez porque sus más felices intérpretes andaban desperdigados y sin orden ni concierto $[\ldots]$ ha hecho el genial Llapisera un espectáculo entusiasta $[\ldots]^{101}$. Tanta popularidad se refleja en el reportaje publicado por Mundo Gráfico ${ }^{102}$, en el que se hace una crítica del espectáculo producido en Valencia el 12.05.1935.

100 El Heraldo (01.07.1935): 4.

101 La Libertad (07.07.1935): 6.

102 El reportaje indica que la presentación se produjo el día 12, no se especifica que qué mes, en Valencia, añadiendo más adelante que el evento se celebró "anteayer". La Hemeroteca Digital de la Biblioteca Nacional de España indica que este reportaje estaría incluido en el número del 03.07.1935, dato que es erróneo. Este evento se celebró efectivamente el día 12 de mayo en Valencia, y no supuso la presentación oficial, ya que se celebraron varios espectáculos previamente en ciudades como Murcia o Sevilla. Sin embargo, no se menciona ni a Aquilino ni a Vilches hasta el reportaje de Mundo Gráfico, por lo que no es posible determinar con certeza si ambos músicos estaban integrados en el espectáculo desde el principio o si se incorporaron en otro momento. En La Voz (06.05.1935): 6; El Heraldo (06.06.1935): 14; El Heraldo (13.05.1935): 5 y 9. 
En este texto, se observa cómo el foco mediático está ahora sobre el coreógrafo Harry Fleming, además de ponerse de manifiesto el cambio de tendencia estética hacia el jazz. Aquilino y Vilches, aunque mencionados, están relegados a un segundo plano, hecho que se observa en el cada vez menor protagonismo de ambos en las distintas crónicas, incluso desapareciendo de ellas.

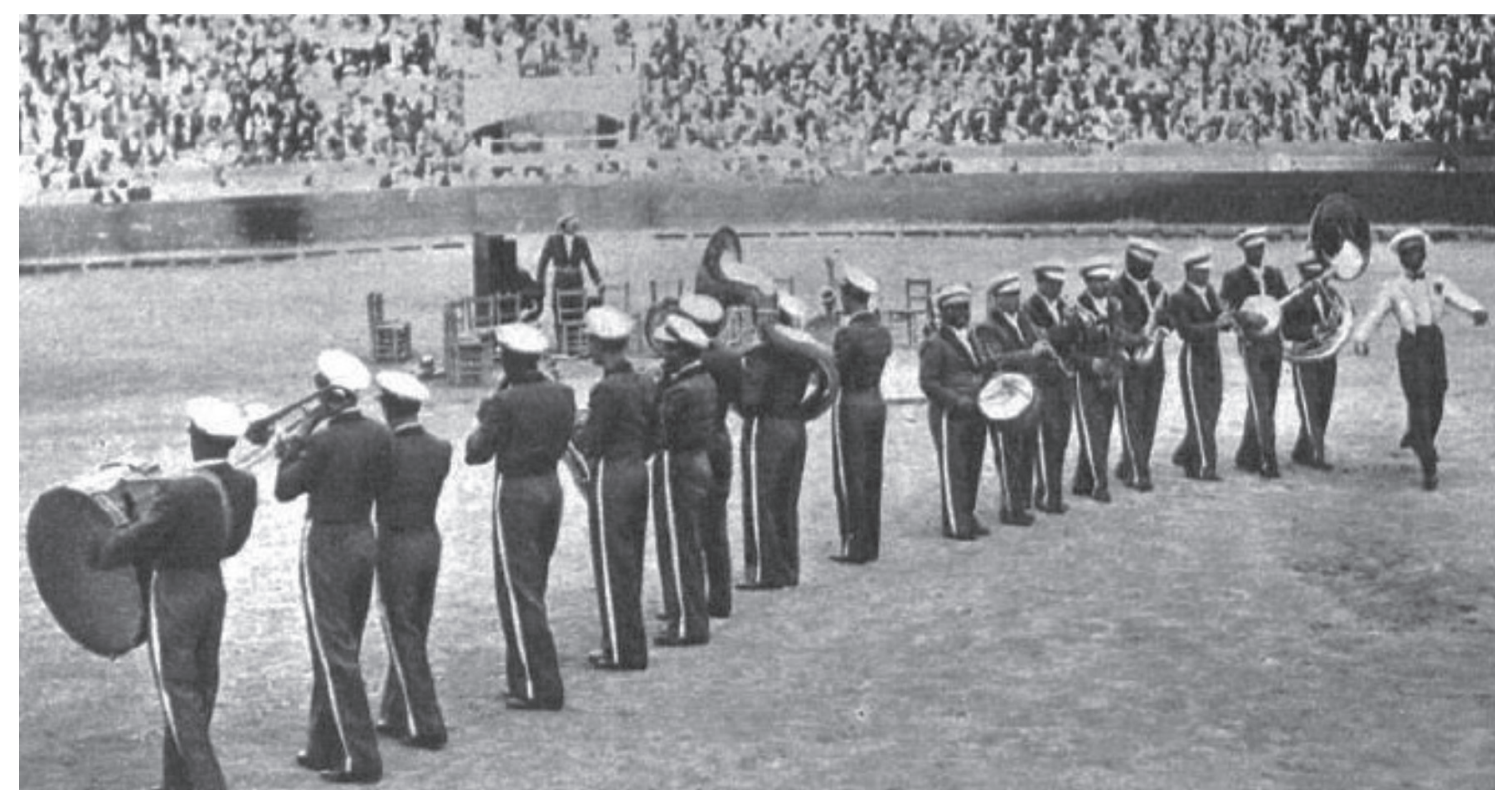

Ilustración 7: Foto de la actuación del espectáculo Universal, el 12.05.1935 en Valencia. Aparece a la derecha Harry Flemming. En Mundo Gráfico, probablemente el 14.05.1935

Aparte de la actividad junto a Llapisera, cuyo espectáculo Universal se despidió, supuestamente, el 24.08.1935 en Madrid ${ }^{103}$, la prensa sigue reflejando los movimientos de Aquilino y Vilches durante ese año. La grabación "Media granaina" de Aquilino sonó varias veces en Unión Radio ${ }^{104}$, además de actuar el 28 y el 29 de diciembre en el teatro Europa como fin de fiesta ${ }^{105}$. Una información sobre Vilches aparece en la edición de El Heraldo del 16.09.1935. Se trata de las impresiones recogidas por el periodista tras una conversación con el saxofonista jiennense, en la cual afirma que tras, terminar los contratos que le mantienen constantemente de viaje, permanecería en Madrid para lanzar composicio-

103 El Heraldo (26.08.1935).

104 Ondas (10.08.1935): 17; (31.08.1935): 17; (05.10.1935): 17; (02.11.1935): 17 .

105 El Heraldo (27.12.1935): 10; El Heraldo (28.12.1935): 10; La Libertad (27.12.1935): 10; La Voz (28.12.1935): 5; La Libertad (29.12.1935): 10 . nes, además de tener en estudio un "desafío artístico"106. El 16 de noviembre de ese año tocó en el festival de la sociedad benéfica de autores de variedades ${ }^{107}$, y el día 28 de diciembre aparece en la publicación Ondas la emisión de un pasodoble llamado "Rafaeliyo", supuestamente compuesto por Vilches ${ }^{108}$.

El claro descenso en la presencia tanto de Vilches como de Aquilino en prensa denota la gradual bajada en su popularidad y la del saxofón flamenco, hasta el punto de que, en el caso del español, se pierde el rastro en los años siguientes. No ocurre así con el cubano, que prosiguió activo aunque su reflejo en la prensa se vio drásticamente disminuido, condicionado por el conflicto bélico que azotaría el país a partir del verano de 1936. El 11.08.1936, Aquilino actuó en el teatro Capitol junto con estrellas como Conchita

106 El Heraldo (16.09.1935): 9.

107 La Libertad (16.11.1935): 6.

108 Ondas (28.12.1935): 12. 
Piquer y Angelillo ${ }^{109}$. Ya en 1937, encontramos a Aquilino actuando en el festival organizado por la Oficina de Propaganda de la Federación Local de Juventudes Libertarias ${ }^{110}$, y participando en otro acto de corte político en Cine Salamanca, en un festival promovido por los obreros de los talleres, parqué, imprenta y colegio de la G. N. R. ${ }^{111}$. Como última referencia ese año, una nueva participación en un festival organizado por una sección de Juventud Socialista Unificada del Sector Sur, acompañado del guitarrista Alfaro ${ }^{112}$. Las últimas referencias a Aquilino aparecen en el 1939, con la guerra ya finalizada. La Vanguardia se hace eco de la presentación de su "Espectáculo 1939" "113, y el ABC de un espectáculo de variedades en el Teatro Maravillas de Madrid, en el que participaría Aquilino ${ }^{114}$. Tras estas referencias, el músico cubano desaparece de la prensa, lo que puede indicar que finalmente abandonara el país, como también hizo Fernando Vilches, en algún momento a partir de finales de 1939. Giró apunta que Aquilino actuó en Cuba en 1953, donde formó parte de una jazz - band ${ }^{115}$, aunque no detalla la procedencia de esta información. Sobre Vilches, del que sí se conoce su entrada en Méjico como exiliado político, se sabe que continuó siendo activo en el país centroamericano, aunque, en ambos casos, no se ha podido determinar el lugar ni la fecha del deceso.

\section{Grabaciones, una aproximación}

La intensa actividad concertística desarrollada tanto por Fernando Vilches como por Aquilino Calzada tuvo su reflejo en la grabación de distintos discos de los que, hasta fechas muy recientes, no se había tenido noticia. Este puede ser el motivo por el que algunas de las obras clave de la historiografía flamenca de los últimos años no registren ni hagan alusión a la existencia y significación históricas de estas grabaciones. Sin embargo, al igual que ocurre en la literatura académica, la información relativa a dichas grabaciones contenida en los discos recopilatorios en los que han sido incluidas, como lugar del registro, publicación, año de grabación o año de edición, vuelve a ser contradictoria, en algunos casos, o simplemente inexistente, en otros. El primer recopilatorio del que tenemos constancia y en el que están incluidas algunas de estas grabaciones tiene como título 5 Guitarras his-

109 La Libertad (11.08.1936): 5.

110 La Libertad (20.02.1937): 3.

111 La Libertad (21.02.1937): 3.

112 La Libertad (13.03.1937): 3.

113 La Vanguardia (12.07.1939): 8; (13.07.1939): 12.

$114 A B C$ (03.11.1939): 13.

115 RADAMÉS, 2007: 62. tóricas, publicado por la discográfica Pasarela en 1995. En este disco, producido por Manuel Cerrejón y coordinado por Luis María de la Cueva Olié, se incluyen cuatro grabaciones realizadas por Fernando Vilches y Ramón Montoya, tituladas "Media Granaína", "Fandanguillos", "Colombianas" y "Peteneras"; además, incluye también dos grabaciones realizadas por Sabicas y El Negro Aquilino: unas bulerías llamadas "María Magdalena" y otro tema llamado también "Media Granaína". La información interior, dedicada a los cinco guitarristas de los que se incluyen temas, resulta incompleta y algo confusa. En el caso de Montoya, indica que en 1936 grabó siete placas como solista, en las que no estarían entonces incluidas las cuatro grabaciones del recopilatorio, y que "en 1927 grabó algunos discos, los mismos que tienen en sus manos" 116 . Al no existir más especificaciones, parece que indica que las grabaciones que no fueran a solo se habrían producido en 1927. Además, en la portada, se indica que el año de grabación de los cortes en los que participa Montoya son de 1925. En relación a Sabicas y Aquilino, no se realiza ningún comentario, más allá de indicar en la portada que las grabaciones de Sabicas son de 1947.

Tres años después del lanzamiento de esta recopilación, se publicó un disco titulado Ramón Montoya. El Genio de la Guitarra flamenca. Grabaciones históricas: 1923 - 1936, por la discográfica Sonifolk. Este disco, de cuya información histórica se encargó José Blas Vega, incluye seis grabaciones de Montoya y Vilches, las cuatro presentes en el disco de Pasarela a las que se suman dos nuevos cortes. Sin embargo, los títulos varían, lo que añade aún más confusión. Blas Vega dedica unas líneas a estas grabaciones, aunque no aclara ni la procedencia ni el año aproximado del registro:

Consideramos de interés especial los tres discos que hizo con el saxofonista Fernando Vilches. Estas grabaciones, muy poco conocidas, llaman vivamente la atención, aparte de su belleza armónica y melódica, por su gran interpretación musical, tanto en concepto como en originalidad y mantenimiento flamenco, construyendo sin duda todo un antecedente histórico de lo que ahora se llama la fusión flamenca.

José Blas Vega indica pues que se trata de tres discos, con lo que es muy probable que el formato fuera el de 78 r.p.m. La duración de los cortes, siempre en torno a los tres minutos, sostendría esta posibilidad ${ }^{117}$, junto con el tipo de calidad de sonido, propia de la década de los 30 . Pero, de

116 CERREJÓN, 1995.

117 Cabe recordar que la duración máxima de un disco de 78 r.p.m. es de algo más de tres minutos por cara. 
nuevo, no se especifica el año concreto de grabación ni el de lanzamiento. $\mathrm{Al}$ indicarse en el título del disco grabaciones históricas: 1923 - 1936, se entiende que, según Vega, estas grabaciones se habrían producido en esa franja temporal. Tres años después, Pasarela lanza un recopilatorio llamado Los cantes hispanoamericanos en el mundo del flamenco: ida y vuelta, de nuevo producido por Cerrejón, y en el que se incluye una grabación llamada "Guajiras", que aunque no estaba recogida en la edición de 5 guitarras históricas, corresponde con la Milonga editada por Sonifolk. Sin embargo, en el interior del libreto, se refiere a esta grabación como "Colombianas". En esta ocasión, se especifica que son de 1933, y se incluye una breve reseña biográfica de Fernando Vilches, previamente mencionada en este texto, refiriéndose a él como gran saxofonista que grabó discos con Marchena y a dúo con Ramón Montoya ${ }^{118}$. Además, según Cerrejón, Vilches sería cubano, y moriría en Méjico en 1975.

En el disco editado por Discmedi en 2002 y dedicado a Sabicas, se incluyen las dos grabaciones del guitarrista junto a Aquilino Calzada presentes en el disco de Pasarela de 1995. Aquilino viene nombrado como Anquelino, y la única información que encontramos es que se grabarían en algún momento entre 1940 y 1950, siendo grabaciones de la casa
MGM, lo que enmaraña un poco más la percepción histórica actual. Un año después, un nuevo recopilatorio de Pasarela llamado Flamenco por Colombianas incluye el corte "Colombianas", siendo la misma grabación que la incluida en 5 guitarras históricas. En 2006, de nuevo a través de Pasarela, encontramos el corte "María Magdalena", por Aquilino y Sabicas, en otro recopilatorio llamada Pasado y presente del Cante Flamenco. En ninguno de estos recopilatorios se añade información complementaria.

En 2007, la compañía Discmedi lanza una recopilación llamada Los grandes de la guitarra flamenca, en cuyo primer volumen encontramos una grabación inédita hasta el momento. Se trataría de un fandanguillo en el que el Negro Anquelino es acompañado por Manolo de Badajoz, aunque, de nuevo, la información relativa a esta grabación es sumamente exigua. En 2008, un recopilatorio de músicas del mundo procedentes de discos de 78 r.p.m. guardados en el archivo de EMI, incluye el tema "Flor de Peteneras", en un disco editado por la discográfica Honest Jon's Records. Aunque se han encontrado más recopilatorios en los que se incluye alguno de estos 9 cortes, no se aporta más información que la anteriormente referida. En la siguiente tabla se especifica el nombre de cada tema en los distintos álbumes comentados:

\begin{tabular}{|c|c|c|c|c|c|c|c|c|c|}
\hline & Intérpretes & $\begin{array}{c}\text { Pasarela } \\
1995\end{array}$ & $\begin{array}{c}\text { Sonifolk } \\
1998\end{array}$ & $\begin{array}{c}\text { Pasarela } \\
2001\end{array}$ & $\begin{array}{c}\text { Discmedi } \\
2002\end{array}$ & $\begin{array}{c}\text { Pasarela } \\
2003\end{array}$ & $\begin{array}{c}\text { Pasarela } \\
2006\end{array}$ & $\begin{array}{c}\text { Discmedi } \\
2007\end{array}$ & $\begin{array}{c}\text { Honest } \\
\text { Jon } 2008\end{array}$ \\
\hline 1 & $\begin{array}{c}\text { Aquilino } \\
\text { Sabicas }\end{array}$ & $\begin{array}{c}\text { María } \\
\text { Magdalena } \\
\end{array}$ & & & $\begin{array}{c}\mathrm{M}^{\mathrm{a}} \\
\text { Magdalena } \\
\end{array}$ & & $\begin{array}{c}\mathrm{M}^{\mathrm{a}} \\
\text { Magdalena } \\
\end{array}$ & & \\
\hline 2 & $\begin{array}{c}\text { Aquilino } \\
\text { Sabicas } \\
\end{array}$ & $\begin{array}{c}\text { Media } \\
\text { Granaína } \\
\end{array}$ & & & $\begin{array}{c}\text { Media } \\
\text { Granaína } \\
\end{array}$ & & & & \\
\hline 3 & $\begin{array}{c}\text { Vilches } \\
\text { Montoya } \\
\end{array}$ & $\begin{array}{c}\text { Colombia- } \\
\text { nas }\end{array}$ & $\begin{array}{c}\text { Flor de } \\
\text { Petenera } \\
\end{array}$ & & & Colombianas & & & $\begin{array}{c}\text { Flor de } \\
\text { Petenera }\end{array}$ \\
\hline 4 & $\begin{array}{l}\text { Vilches } \\
\text { Montoya } \\
\end{array}$ & $\begin{array}{c}\text { Media } \\
\text { Granaína } \\
\end{array}$ & $\begin{array}{c}\text { Media } \\
\text { Granaína } \\
\end{array}$ & & & & & & \\
\hline 5 & $\begin{array}{c}\text { Vilches } \\
\text { Montoya } \\
\end{array}$ & $\begin{array}{c}\text { Fandan- } \\
\text { guillos }\end{array}$ & $\begin{array}{c}\text { Por } \\
\text { Fandangos } \\
\end{array}$ & & & & & & \\
\hline 6 & $\begin{array}{l}\text { Vilches } \\
\text { Montoya }\end{array}$ & Peteneras & $\begin{array}{c}\mathrm{Mi} \\
\text { Colombiana }\end{array}$ & & & & & & \\
\hline 7 & $\begin{array}{l}\text { Vilches } \\
\text { Montoya }\end{array}$ & & Fandangos & & & & & & \\
\hline 8 & $\begin{array}{c}\text { Vilches } \\
\text { Montoya }\end{array}$ & & Milongas & Guajiras & & & & & \\
\hline 9 & $\begin{array}{l}\text { Aquilino } \\
\text { M. de } \\
\text { Badajoz }\end{array}$ & & & & & & & $\begin{array}{l}\text { Fandan- } \\
\text { guillo }\end{array}$ & \\
\hline
\end{tabular}

Tabla 1: Grabaciones y título de los cortes

118 CERREJÓN, 1995. 
Como se puede observar, tanto en la tabla como en el análisis previo de la información contenida en los distintos libretos, el cruce de datos no concordantes es constante, lo que seguro ha contribuido a la confusión general reflejada por la bibliografía disponible al respecto. Sin embargo, se puede indagar un poco más al consultar los fondos de centros de Investigación como la Biblioteca Nacional de España o el Centro de Documentación Musical de Andalucía. La presencia de algunas de las grabaciones a las que nos referimos tanto en forma de disco físico como en catálogos resulta esencial para datar, de la manera más precisa posible, las grabaciones, si bien su rastro en las publicaciones periódicas de la época también pueden ayudar a arrojar luz sobre este asunto.

En general, resulta lógico pensar, una vez adquirida la perspectiva histórica, que el grueso de estas grabaciones fuera registrado durante o poco después del auge del saxofón flamenco, en 1932. Es el caso de los cortes Por Fandangos y Por Peteneras, tal y como vienen reflejados en el disco de 78 r.p.m. conservado en la Biblioteca Nacional. Publicados por la Compañía del Gramófono, no están registrados en el catálogo de Discos La Voz de su Amo de enero de 1932, mientras que sí lo están en el de enero de 1933. Además, la publicidad incluida en algunos medios de prensa de la época y a la que nos hemos referido a lo largo de este artículo, hace referencia a estas grabaciones el día de Nochebuena de 1932, y la víspera del Día de Reyes de 1933, en la que se aclaran los títulos de "Por Fandangos" y "Por Peteneras", añadiéndoles los nuevos nombres "Mi Colombiana" y "Flor de Peteneras", como viene indicado en el disco de Sonifolk:

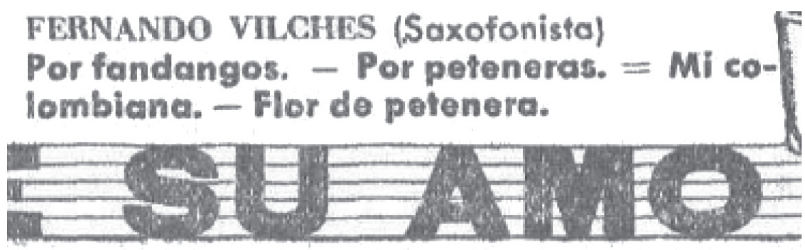

Ilustración 8: Publicidad del disco de Fernando Vilches en El Heraldo (05.01.1933)

Por tanto, es más que probable que, al menos estos dos temas, se grabaran durante 1932 y se publicaran a final de año. La presencia del corte "Mi Colombiana" también sirve como indicador para datar esta grabación, ya que la colombiana fue presentada a la sociedad flamenca en 1931 por El Niño de Marchena, registrada en junio de 1931 en la referencia AE - 3608 con el título de "Mi Colombiana"119. Del resto de cortes de Vilches y Montoya registrados en los distintos recopilatorios no se ha encontrado reflejo en la prensa de la época, lo que tampoco puede considerarse como un indicador definitivo sobre su posible publicación o no publicación. Vilches registró otras grabaciones junto con Marchena y Ramón Montoya, en un contexto más próximo al pasodoble que, pese a aparecer en los distintos catálogos, no tuvieron prácticamente eco en los distintos periódicos. Sin embargo, lo que resulta más extraño es que tampoco existiera ningún reflejo en la programación radiofónica de la época, más allá de los temas referidos, ni en los posteriores catálogos de La Voz de su Amo. Al realizar un análisis auditivo a los distintos temas, se observa cierta homogeneidad en el tono, a pesar de que con casi toda seguridad las grabaciones procedan de tres discos de 78 r.p.m. con diferentes grados de degradación y tratamientos distintos a la hora de ser digitalizados. Utilizando la única fuente en la que están incluidos los seis cortes ${ }^{120}$, los picos de frecuencias marcados por la guitarra y el saxofón coinciden en gran medida, lo que podría ser un indicador de que se grabaran en la misma sesión.

119 MOLINA y ESPÍN, 1992: 153

120 Se trata de la edición de Sonifolk. Es de suponer que, pese a proceder de tres fuentes distintas, la digitalización y proceso se han producido de una forma similar. 


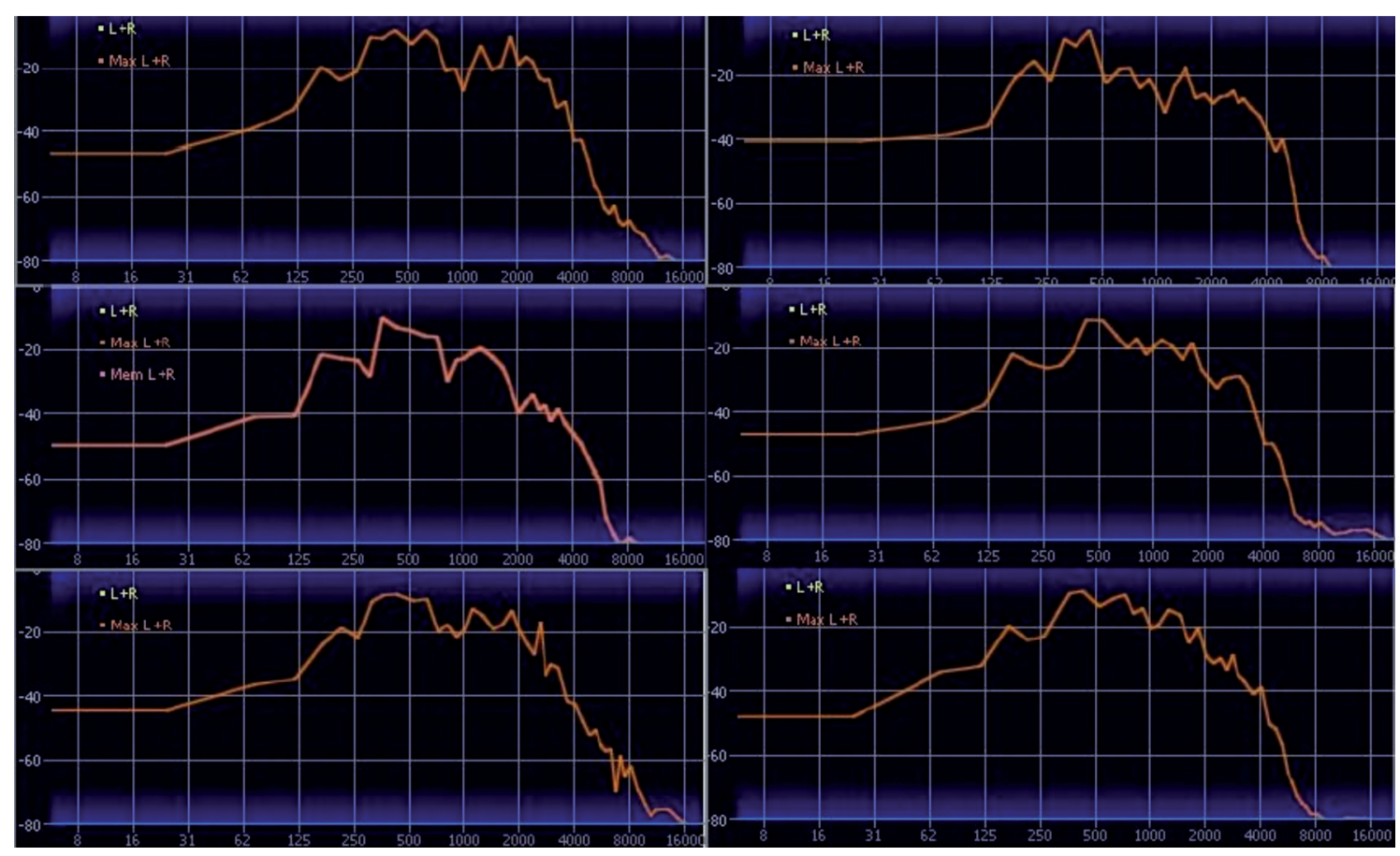

Ilustración 9: Respuesta de frecuencia de las seis grabaciones contenidas el el disco de Sonifolk, realizadas con el programa PAZ Analyzer de Waves

Por tanto, las seis grabaciones de Vilches y Montoya en las que el saxo emula al cantaor acompañándose de una guitarra flamenca se realizarían probablemente entre 1932 y 1933, aunque la publicación de las cuatro restantes se produciría a partir del año 33. En relación a las grabaciones de Aquilino, es también probable que la grabación junto a Manolo de Badajoz se produjera entre 1932 y 1939, aunque la popularidad del músico y el auge del saxofón flamenco sugieren que ocurriera más temprano que tarde, dentro de esta franja. De nuevo, es sorprendente el reflejo nulo en los distintos catálogos de las casas Odeón, Fonotipia, La Voz de su Amo o Pathé, lo que podría incluso indicar que se tratara de una grabación privada o que no se editara en su momento. La grabación de Aquilino y Sabicas, considerando que éste último se desplazó a América junto a Carmen Amaya en 1936, permaneciendo allí hasta $1950^{121}$, probablemente se realizaría fuera de España ${ }^{122}$, ya en la década de 1940. Aun-

121 RÍOS RUIZ, 2002: 387.

122 Como se indica en el recopilatorio de Discmedi, la grabación se podría haber realizado en Estados Unidos, aunque el catálogo de MGM, en su primer volumen que cubre la franja temporal comprendida entre 1946 y 1960 , solo registra una serie de grabaciones realizadas por que Cerrejón, como se ha observado, apunta a 1947 como año de grabación ${ }^{123}$, información que concuerda tanto con la información en el disco de Discmedi como con la propia biografía del guitarrista, el catálogo de MGM no recoge estas grabaciones. Puede que estén registradas en otro catálogo o que, en realidad, procedan de otra casa discográfica, aunque este extremo no se ha podido precisar. Aquilino también grabó al menos cuatro placas, agrupadas en dos discos de 78 r.p.m., acompañado por el pianista Beltrán, que si bien están catalogadas como publicadas en 1932, no encontramos reflejo en emisiones radiofónicas hasta 1935.

\section{Conclusiones}

La existencia de un grupo de grabaciones en las que el saxofón toma el papel del cantaor acompañado de una guitarra flamenca ha obligado a una parte de la historiografía flamenca a revisar el origen del concepto de fusión. La aproxi-

Sabicas en 1960, sin indicar nada de una posible grabación con Aquilino en la franja 46 - 50. RUPPLI y NOVITSKY, 1998: 809-810. 123 CERREJÓN, 1995. 
mación de músicos como Pedro Iturralde o Jorge Pardo desde finales de los 60 hasta la actualidad tuvo unos precedentes que no comenzaron a popularizarse al menos hasta 1995, con el lanzamiento del recopilatorio 5 Guitarras históricas, producido por Manuel Cerrejón. Sin embargo, los confusos datos que se sucedieron, relativos tanto a la identidad y biografía de los músicos implicados como a la naturaleza y procedencia de las propias grabaciones, han dificultado enormemente su percepción histórica. Tras una exhaustiva y tediosa revisión de la hemeroteca, se ha podido reconstruir el auge del saxofón flamenco ocurrido en 1932 y protagonizado por estos dos músicos, Fernando Vilches Silva y Aquilino Calzada González, más conocido como El Negro Aquilino. De Fernando Vilches, un músico del que se desconocía prácticamente todo y cuya identidad ha llegado a ser confundida con la del propio Aquilino, se ha desvelado su lugar y fecha de nacimiento, su actividad como músico en el Ejército y su exilio a Méjico en los últimos compases de la Guerra Civil Española. De Aquilino no se han podido recabar tantos datos biográficos, si bien su fuerte presencia en la prensa española de la Segunda República ha arrojado información sobre su persona. Ambos tuvieron una relación inicial de rivalidad y, posteriormente, de cooperación; y a ambos es atribuible la creación y éxito del saxofón no sólo interpretando flamenco, sino acompañándose de guitarristas históricos del género, como Sabicas o Ramón Montoya. El posterior conflicto bélico y las importantes secuelas del Franquismo y la posguerra para la historiografía contribuyeron a enterrar esta expresión prematura del mundo flamenco, y aunque las pretensiones originales fueran indudablemente comerciales, la realidad es que se produjo ese contacto entre flamencos y saxofonistas, que probablemente tuvieran como referencia las orquestas de jazz americano de los años 20. Además, Vilches inicialmente, y Aquilino, algo después, se introdujeron en el ámbito flamenco, colaborando de forma regular con diversos artistas en presentaciones en directo y grabaciones de índole más orquestal.

En relación a las grabaciones que han llegado a nuestros días, la gran confusión existente en las diversas fuentes ha sido parcialmente aclarada. Se trata de un total de nueve cortes, seis atribuibles a Vilches y Ramón Montoya, dos a Aquilino junto a Sabicas, y uno a Aquilino junto a Manolo de Badajoz. De los seis cortes de Vilches y Montoya sólo se ha podido contrastar la fecha y publicación de dos de ellos, "Flor de Petenera" y "Mi colombiana", aunque es muy probable que los otros cuatro se grabaran en la misma sesión y se publicaran más adelante, o incluso en otro país. La grabación de Aquilino con Manolo de Badajoz es de la que menos información se ha podido recabar, aunque tanto por el sonido como por los datos históricos recogidos se puede establecer su grabación en la franja comprendida entre 1932 y 1939. Los dos cortes de Sabicas con Aquilino se grabarían probablemente en Estados Unidos, lugar de residencia del guitarrista navarro, durante la segunda mitad de la década de los cuarenta, según las fuentes discográficas disponibles. En cualquier caso, el trabajo en este sentido debe continuar con el fin de datar con precisión la fecha de publicación de esta serie de grabaciones. Un análisis exhaustivo a nivel musical puede ser planteado, con el fin de comparar los trazos melódicos de ambos saxofonistas con las melodías interpretadas por cantaores de la época, como Manuel Vallejo y el Niño de Marchena, lo que también ofrecería nuevas perspectivas. Finalmente, es necesario otorgar a este tipo de representaciones el peso que merecen en la historiografía del flamenco, ya que representan una apertura temprana en un arte que generalmente ha sido percibido como cerrado, sentando las bases de una fusión o contacto posterior. Fernando Vilches y Aquilino Calzada se introdujeron en el mundo del flamenco de la época, y cabe pensar qué hubiera ocurrido si los acontecimientos relativos a la Guerra Civil y sus consecuencias posteriores hubieran sido otras. Probablemente, habría que contar otra historia del flamenco.

\section{Bibliografía}

Blas Vega, José, y Ríos Ruiz, Manuel, Diccionario enciclopédico del Flamenco. Tomo II. Madrid, Cinterco, 1988.

Calvo, Pedro y Gamboa, José Manuel, Historia Guía del Nuevo Flamenco. El duende de ahora. Madrid, La Encrucijada, 1994.

Clemente, Luis, "Jazz-flamenco Azulado", en Julián Ruesga Bono (ed.), In'n Out. In - fusiones de jazz. Sevilla, Artefacto, 2010, 77 - 110.

Díaz Ayala, Cristóbal, Cuando salí de La Habana: 1989 1997: cien años de música cubana por el mundo. San Juan, Puerto Rico, Fundación Musicalia, 2001.

Eli, Victoria y Alfonso Rodríguez, $\mathrm{M}^{\mathrm{a}}$ de los Ángeles, $L a$ música entre Cuba y España. Tradición e innovación. Madrid, Fundación Autor, 1999.

Gamboa, José Manuel, Una Historia del Flamenco. Espasa. Madrid, 2005.

García Martínez, José María, Del Fox Trot al Jazz Flamenco: el jazz en España: 1919 - 1996. Madrid, Alianza Editorial, 1996.

Herrero, Germán, De Jerez a Nueva Orleans. Análisis comparativo del flamenco y del jazz. Granada, Editorial Don Quijote, 1991.

Molina, Romualdo y Espín, Miguel, Flamenco de ida y vuelta. Sevilla, Guadalquivir, 1992.

Pohren, Donn E., Paco de Lucía y familia: el plan maestro. Madrid, Sociedad de Estudios Españoles, 1992. 
Radamés, Giró, Diccionario enciclopédico de la música en Cuba. Tomo 1. La Habana, Letras cubanas, 2007.

Ríos Ruiz, Manuel, El gran libro del flamenco. Volumen I: Intérpretes. Madrid, Calambur, 2002a.

Ríos Ruiz, Manuel, El gran libro del flamenco. Volumen II: Intérpretes. Madrid, Calambur, 2002b.

Ruppli, Michel y Novitsky, (eds.), The MGM Labels. A Discography. Volume 1, 1946-1960. London, Greenwood Press, 1998.

Salinas Rodríguez, José Luis, Jazz, flamenco, tango: las orillas de un ancho río. Madrid, Catriel, 1994.

Zabala, Fernanda, 125 Valencianos en la Historia. Valencia, Carena Editors, 2003.

Zagalaz, Juan, The jazz - flamenco connection: Chick Corea and Paco de Lucía between 1976 and 1982, Journal of jazz studies, 8/1 (2012), 33-54.

\section{Discografía}

Aquilino, Milonga - Media Granadina. Odeón, 183.534, 1932.

Aquilino, Fandanguillos - Guajiras. Odeón, 183.473, 1932.

Cerrejón, Manuel (productor), 5 Guitarras Históricas. Pasarela, PSC 6057 - 10, 1995.

Cerrejón, Manuel (productor), Los Cantes iberoamericanos en el mundo del flamenco. Pasarela, CDP 8/858, 2001.
Cerrejón, Manuel (productor), Flamenco por Colombianas. Pasarela, CDP 1/931, 2003.

Coltrane, John, Olé Coltrane. Atlantic LP 1373, 1961.

Davis, Miles, Kind of blue. CL 1355, 1959.

Davis, Miles, Sketches of Spain. CK 65142, 1960.

De Lucía, Paco, Paco de Lucía interpreta a Manuel de Falla. Philips 836032 - 2, 1978.

De Lucía, Paco, Solo quiero caminar. Philips 810009 - 2, 1981.

Iturralde, Pedro, Jazz Flamenco. HH (S) 11 - 128, 1967.

Iturralde, Pedro, Jazz Flamenco. Vol. 2. HHS 11 - 151, 1968.

Iturralde, Pedro, Flamenco Jazz Pedro Iturralde Quintet Paco de Lucía. SB 15143 ST, 1968.

Montoya, Ramón, Ramón Montoya. El Genio de la Guitarra Flamenca. Grabaciones históricas 1923 - 1936. Información histórica por José Blas Vega. Sonifolk, 20130, 1998.

Pardo, Jorge, Huellas. Cabra Road, 2012.

Recopilatorio, Pasado y presente del cante flamenco. Edición especial con motivo de la XIV bienal de flamenco de Sevilla. Pasarela, CDPA - 1038, 2006.

Sabicas, Grabaciones discos High Fidelity - MGM. 1940 1950. Discmedi DM 617 02, 2002.

Vilches, Fernando y Bregel, Enrique, Por Fandangos - Por Peteneras. Disco Gramófono, AE4136, 1932.

Recibido: 15.01.2013

Aceptado: 25.08.2015 